response obtained with recent inactivated simian and human immunodeficiency viral vaccines ${ }^{11-13}$ could have included a CTL component, because the replicating forms of these viruses fuse directly with the plasma cell membrane ${ }^{14}$. But the use of killed HIV preparations for human vaccines carries considerable risk, and structures like the ISCOMs bearing only selected viral components may be attractive alternatives. In this regard the success of using ISCOMs to introduce whole viral proteins into cells for induction of CTL may be important, because it is likely that several T-cell epitopes will be needed both for priming and to overcome allotype restriction. Nevertheless, inclusion of key epitopes may be desirable and the target region described by Takahashi et al. ${ }^{1}$ is an important one because it is immunodominant for both neutralizing antibodies and CTL. Its drawback lies in its variability, although this might be overcome with appropriate cocktails ${ }^{15-17}$.

These results will stimulate a great deal of further research. But their ultimate value may depend on the extent to which TRANSCRIPTION INITIATION

\section{In search of the single factor}

\section{Marvin R. Paule}

EUKARYOTIC RNA polymerases are unable to recognize and transcribe from promoters at the beginning of genes without the aid of additional proteins, the general transcription factors. The three polymerases found in eukaryotic nuclei transcribe different sets of genes, and the number of factors associated with the initiation process increases as the variety of genes transcribed by the polymerase increases. Until now, the sole exception to the requirement for several transcription factors in eurkaryotes was that of ribosomal RNA transcription by polymerase I from Acanthamoeba, for which a single ancillary protein (TIF-I) is required ${ }^{1,2}$. But Kassavetis et al. $^{3}$ now report that only one of the three factors involved in transcription mediated by polymerase III in yeast, TFIIIB, is truly a transcription initiation factor. The others (TFIIIA and TFIIIC) are assembly factors responsible for loading the fundamental factor onto its site on the DNA. This observation means that the mechanisms described for rRNA transcription in Acanthamoeba, and now for transcription of yeast polymerase III genes, may be universal for eukaryotic transcription initiation - that is, that only one factor bound upstream of the transcription start site (dubbed +1 ) is needed to direct the polymerase to its binding site. The fundamental initiation factor can direct several rounds of initiation, and - most importantly - Kassavetis et al. show the addi- the alternative pathways can be used (see figure), particularly in vaccine development and immunotherapy.

Dani P. Bolognesi is in the Department of Surgery, and the Department of Microbiology and Immunology, Box 2926, Duke University Medical Center, Durham, North Carolina 27710, USA

1. Germain, R. Nature 322, 687-689 (1986)

2. Takahasi, H. et al. Nature $344,873-875$ (1990)

3. Staerz, U.D., Karasuyama, H. \& Garner, A.M. Nature 329. 449-451 (1987)

4. Deres, K. et al. Nature 342, 561-564 (1989).

5. Nuchtern, J.G., Biddison, W.E. \& Klausner, R.D. Nature 343, 74-76 (1990)

6. Polydefkis, M. et al. J. exp. Med. 171, 875-887 (1990).

7. Jin, Y. et al. J. exp. Med. 168, 293-306 (1988)

8. Long, E. O. \& Jacobson, S. J. Immun. 10, 45-48 (1989).

9. Yewdell, J.W., Bennink, J.R. \& Hosaka, Y. Science 239, $637-639(1988)$

10. Sekaly, R.P. et al. Proc natn. Acad Sci. US.A.85, 1209-1212 (1988)

11. Derosiers, R.C. et al. Proc. natn. Acad. Sci. U.S.A. 86 6353-6357 (1989)

12. Murphy-Corb, M. et al. Science 246, 1293-1297 (1989).

. Gibbs, C.J. et al. Vth Int. Conf. on AIDS, Montreal, Canada (Abstr. C. Th. C.0. 46, 1989)

14. Stein, B.S. et al. Cel/ 49, 659-668 (1987)

15. Putney, S.D. et al. Vth International conference on AIDS, Montreal, Canada (Abstr. W.C.O. 18, 1989).

16. Zwart, G. et al. Lancet II, 474 (1990).

17. Devash, Y. et al. AlDS Res. hum. Retrovir. (in the press)
They stripped TFIIIA and TFIIIC from the templates by using high salt concentration or heparin, and then isolated the DNA-protein complexes by sizeexclusion chromatography. Only TFIIIB complexes remained, and surprisingly, they retained the capacity for several rounds of transcription. The factors that had been stripped from the template were able to assemble fresh TFIIIB on a new template; TFIIIA and TFIIIC are therefore assembly factors, and are not required for transcription initiation per se.

Pre-initiation complexes of TRNA and 5S RNA transcription in yeast ${ }^{3.5 .10}$ and rRNA transcription in Acanthamoeba ${ }^{2,11,12}$ have been 'visualized' using footprinting techniques. Yeast TFIIIB was found to protect the DNA template between about 10 and 40 base pairs upstream of +1 on $5 \mathrm{~S}$ RNA and tRNA genes. The single Acanthamoeba rRNA transcription initiation factor (TIF-I) protected between about -12 and -70 base pairs, forming a stable complex which remained bound through several rounds of transcription (see figure). The two factors therefore form similar complexes upstream of the transcription start site.

The first footprints of a eukaryotic polymerase on a promoter demonstrated that Acanthamoeba RNA polymerase binds just downstream of TIF-I, protecting over $34 \mathrm{bp}$, to +18 , from DNase I digestion ${ }^{2}$. Replacement of the protected region with a variety of bacterial sequences showed that there are no DNA sequence-dependent contacts made by polymerase, but instead, the enzyme is positioned on the promoter by proteinprotein contacts with TIF-I ${ }^{13}$. Similarly, polymerase III protects 23 bp (for $5 \mathrm{~S}$ RNA genes) or 28 bp (for tRNA genes) of DNA just downstream of TFIIIB. Earlier studies by Sakonju et ll $^{1+}$ suggest that the binding of polymerase to $5 \mathrm{~S}$ RNA genes is also sequence-independent. To prove that the extended footprints are due to protection by polymerase and not to a conformational change in the previously bound factor, the polymerase I (refs 11, 13) and III (ref. 2) systems were supplied with a nucleotide mixture that allows the polymerase to make only a short RNA product. Addition of a mixture lacking GTP resulted in the polymerase stalling part way down the template. As predicted, the putative polymerase footprints moved part way down the DNA. Addition of all four nucleoside triphosphates resulted in total disappearance of the polymerase footprints.

Significantly, the Acanthamoeba TIF-I footprint remains unaltered during initiation, showing that TIF-I remains bound through several rounds of transcription $^{11,12}$. In the polymerase III systems, the TIIIB footprint was also unchanged after partial translocation of the polymerase down the template. Furthermore, 


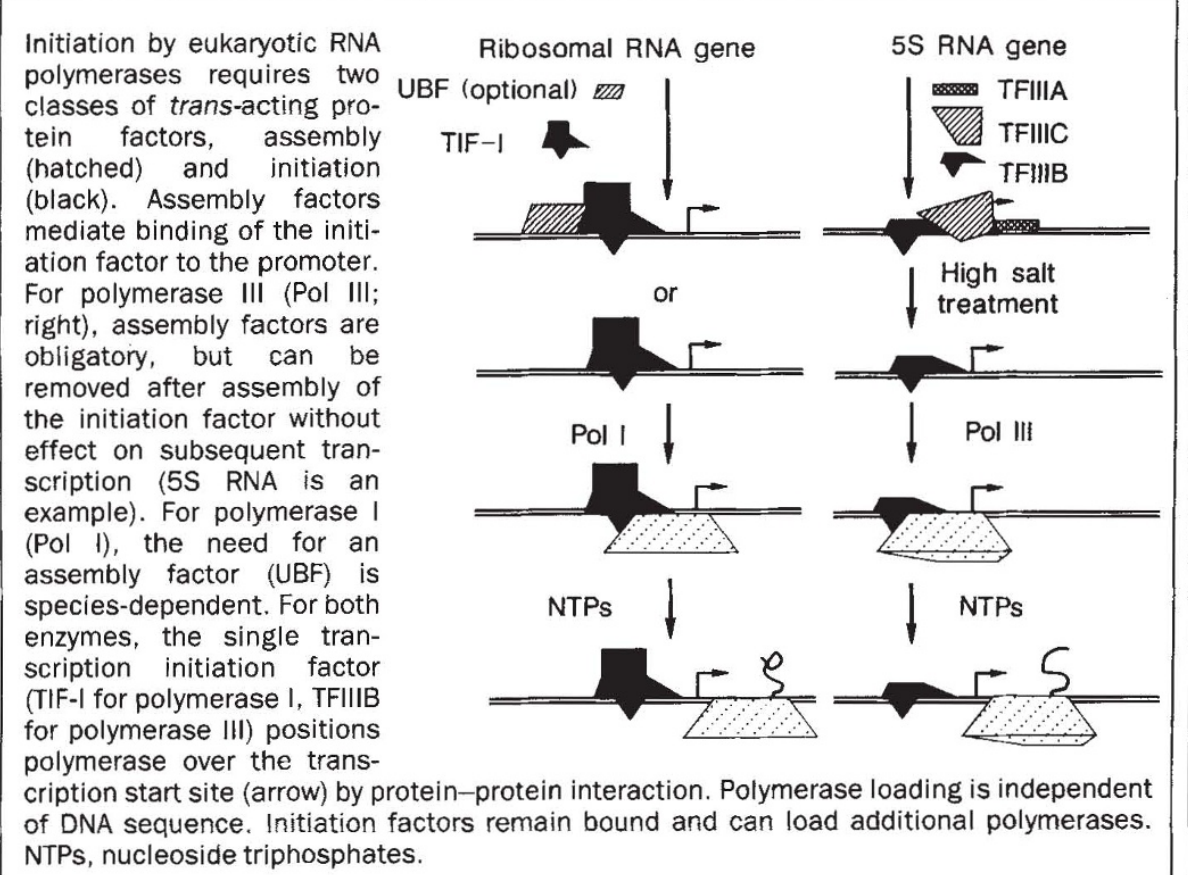

Kassavetis et al. obtained nearly equal numbers of transcripts from complete and stripped templates ${ }^{3}$. Therefore, assembly factors are unnecessary for repetitive transcription initiation, even in systems that require them for preinitiation complex formation, because the initiation factors do not cycle with each round of transcription.

What happens to assembly factors during transcription in vivo? Those bound upstream of the transcription start site, as on the rRNA genes, do not interfere with transcription. But assembly factors on $5 \mathrm{~S}$ RNA and tRNA genes bind within the transcribed sequence, to the internal control region $(\mathrm{ICR})^{15}$. Just how polymerase III is able to transcribe through the factors that bind to the ICR has been a puzzle. A clue comes from recent in vivo footprinting data ${ }^{16}$ suggesting that the assembly proteins do not remain tightly bound. This is in keeping with the latest discovery that the factors bound to the ICR can be removed without affecting subsequent initiations, showing that they are not transcription factors, but assembly factors. On the other hand, there is no evidence from studies in vitro showing that the assembly factors are released, so this remains an open question.

Are the same assembly factors used for all polymerase III genes? U6 small nuclear RNA, a component of spliceosomes, is transcribed by polymerase III, but it does not have the usual ICR sequences necessary for TFIIIA or TFIIIC binding ${ }^{17-19}$. Similar observations have been made for 7SL (ref. 20) and 7SK (ref. 21) genes. It seems that transcription of the U6 RNA gene does not require these assembly factors ${ }^{18,22}$, although it still needs TFIIIB. The U6 RNA gene, however, has promoter elements in the upstream flanking region, and some of these function with transcription factors normally associated with RNA polymerase $\mathbf{I I}^{17,23}$. So alternative assembly factors may suffice for U6 RNA transcription.

It now remains to be seen whether the mechanism of transcription initiation that has now been established for polymerase I and III holds for polymerase II.

Marvin R. Paule is in the Department of Biochemistry, Colorado State University, Fort Collins, Colorado 80523, USA.

1. Iida, C.T., Kownin, P. \& Paule, M.R. Proc. natn. Acad. Sci. U.S.A. 82, 1668-1672 (1985).

Bateman, E., lida, C.T., Kownin, P. \& Paule, M.R. Proc natn. Acad. Sci. U.S.A. 82, 8004-8008 (1985).

3. Kassavetis, G.A., Braun, B.R., Nguyen, L.H. \& Geiduschek, E.P. Cell60, 235-245 (1990).

4. Bieker, J.J., Martin, P.L. \& Roeder, R.G. Cell 40, 119 127 (1985).

5. Braun, B.R., Riggs, D.L., Kassavetis, G.A. \& Geiduschek, E.P. Proc. natn. Acad. Sci. U.S.A. 86, 2530-2534 (1989).

6. Jantzen, H.-M., Admon, A., Bell, S.P. \& Tjian, R. Nature 344, 830-836 (1990)

. Pikaard, C.S., McStay, B., Schultz, M.C., Bell, S.P. \& Reeder, R.H. Genes Dev. 3, 1779-1788 (1988)

8. Bell. S.P., Pikaard, C.S., Reeder, R.H. \& Tjian, R. Cell 59, 489-497 (1989) B. Molec. cell. Biol. 9, 5093-5104 (1990).

10. Kassavetis, G.A., Riggs, D.L., Negri, R., Nguyen, L.H. \& Geiduschek, E.P. Molec. cell. Biol. 9, 2551-2566 (1989).

11. Bateman, E. \& Paule, M.R. Cel/ 47, 445-450 (1986).

12. Bateman, E. \& Paule, M.R. Molec. cell. Biol. 8, 19401946 (1988).

13. Kownin, P. Bateman, E. \& Paule, M.R. Cell 50, 693699 (1987).

14. Sakonju, S., Bogenhagen, D.F. \& Brown, D.D. Cell 19 13-25 (1980)

15. Geiduschek, E.P. \& Tocchini-Valentini, G.P. A. Rev. Biochem. 57, 873-914 (1988) 3244-3252 (1990).

17. Caron, P.S et al. Cell 51, 71-79 (1987)

18. Reddy, R. J biol. Chem. 263, 15980-15984 (1988)

18. Runkel, G.R., Maser, R.L., Calvet, J.P. \& Pederson, T. Proc. natn. Acad. Sci. U.S.A. 83, 8575-8579 (1986).

20. Ulliu, E. \& Weiner, A.M. Nature 318, 371-374 (1985).

21. Murphy, S., di Liegro, C. \& Melli, M. Cell 51, 81-87 (1987)

2. Moenne, A et al EMBO J.9, 271-277 (1990)

23. Bark, C., Weller, J., Zabielski, J., Larson, L. \& Pettersson, U. Nature 328, 356-359 (1987).
Pape, L.K. Windle, J.J., Mougey, E.B. \& Sollner-Webb,

16. Huibregtse, J.M. \& Engelke, D.R. Molec. cell. Biol. 9

\section{Shaky ground}

ONE of the many hazards of earthquakes is the catastrophic 'liquefaction' of soil. The rapid succession of shocks shakes up the soil, mobilizes its water content, and sets it briefly flowing like a liquid. Buildings and structures previously supported on it are wrecked.

Daedalus is now taming this treacherous phenomenon. DREADCO's engineers are setting arrays of dynamite charges in soils ranging from sensitive sands and silts to well-consolidated clay. They then fire the charges in rapid succession, and examine the effects on test buildings and instruments scattered about the site. Their aim is to discover the frequency and amplitude of shock that best liquefies each type of soil.

Earthquake-levels of energy should not be needed. An optimized sequence of explosions, well tuned to the soil in question, should liquefy it very efficiently for a short while, with little other disturbance. Like a phased array, the charge pattern could be fired so as to launch its major disturbance in any desired direction, or even vertically downwards.

The way will be open for a whole new style of civil engineering, starting with elementary demolition. How elegant to liquefy the ground beneath some tower block or urban monstrosity, so that it simply sinks into the earth and vanishes without trace! Sadly, most monstrosities are not nearly heavy enough to sink completely into a cavity of liquefied soil. They would merely capsize and break up, leaving a flotsam of rubble.

Engineering construction could also be simplified. A complete array of piles could be sunk into liquefied soil in one operation, to be firmly held when it set again. Pipes and cables could be laid out around a site, and sunk to the required depth by a horizontally propagated wave of vibration, briefly liquefying the soil they lay on. Building foundations, erected on the surface, could be dropped to the damp-course by sudden liquefaction. Indeed, if designed for hydrostatic stability, an entire building might be constructed above ground, and 'launched' into the liquefied soil with speeches and champagne. It would then sink to its calculated Plimsoll line, submerging basement and foundations to their proper depth.

Daedalus feels that even agriculture could benefit. Dynamite has already been used for 'ploughing' in an experimental manner. But the complete fluidization of a field by a shallow omnidirectional shockpattern should be far more efficient. Weeds would be overturned and ploughed in, pest larvae killed or severely shaken, deep nutrients mobilized, and the earth aerated, all in a few seconds. Even hidden archaeological remains might come floating to the surface.

David Jones 